\title{
Cellulose Acetate of Rice Husk Blend Membranes: Preparation, Morphology and Application
}

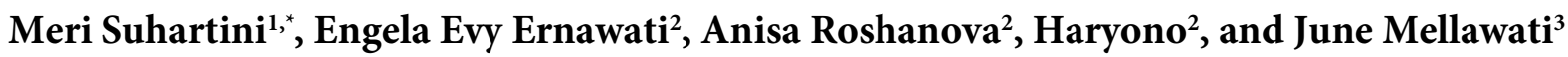 \\ ${ }^{1}$ CIRA, National Nuclear Energy Agency, Lebak Bulus Raya No. 49, Pasar Jumat, \\ PO Box 7002, JKSKL, South of Jakarta, Jakarta 12070, Indonesia \\ ${ }^{2}$ Department of Chemistry, Faculty of Mathematics and Natural Sciences, Padjadjaran University, \\ Jatinangor 45363, West Java, Indonesia \\ ${ }^{3}$ CTRSM, National Nuclear Energy Agency, Lebak Bulus Raya No. 49, Pasar Jumat, PO Box 7043 JKSKL, \\ South of Jakarta, Jakarta 12070, Indonesia
}

\author{
* Corresponding author: \\ tel: $+62-151657145$ \\ email:meri@batan.go.id \\ Received: July 1, 2019 \\ Accepted: August 30, 2019 \\ DOI: $10.22146 /$ ijc. 47185
}

\begin{abstract}
Cellulose acetate blend membranes in this study was synthesized from cellulose acetate (CA) of rice husk and NaA zeolites (Z) with N,N'-Methylene bis acrylamide (MBA) as the cross-linker agent and gamma-rays from cobalt-60 source as the reaction initiator. Application of the membrane was carried out to increase the concentration of vetiverol in vetiver oil. The steps in this study were isolation of the cellulose rice husk with alkali treatment, delignification, acetylation, preparation of the cellulose acetate-NaA zeolites NaA-membrane by inverse phase technique, addition of $N, N$-Methylene bis acrylamide, and irradiation by gamma-rays. Swelling degree, crosslinking yield, tensile strength, membrane performance, FTIR, and SEM analysis were observed. The results showed that the optimal irradiation dose for the synthesis the $C A$ $Z-M B A$ membrane was $20 \mathrm{kGy}$. The CA-Z-MBA membrane had a swelling degree of $4.44 \%$, tensile strength of $656.40 \mathrm{~kg} / \mathrm{cm}^{2}$, and crosslinking yield of $6.61 \%$. Performance of the CA-Z-MBA membrane reached the flux of $60.58 \mathrm{~g} / \mathrm{m}^{2} . h$, permeate concentration (CP) of $11.67 \%$, and the CP increase 5 times from $2.40 \%$ to $11.67 \%$.
\end{abstract}

Keywords: cellulose acetate membrane; NaA zeolites; gamma-rays; vetiver oil

\section{- INTRODUCTION}

The cellulose acetate membrane is one of the hydrophilic membranes. A hydrophilic membrane has an active polar side, which interacts with a polar molecule or compound. The interaction between the penetrant and the membrane can occur through a chemical bond, the hydrogen bond. The hydrophilic property of the cellulose acetate membrane affects the ease of interaction and diffusion of molecules or penetrant compounds in the membrane if each membrane and solute has similarities or differences in polarity or charge [1]. Cellulose acetate membranes have high water absorption rates, weak electrical resistance, and limited heat and chemical resistance. The properties of water resistance increase with the increasing degree of acetylation and its strength can last up to $60{ }^{\circ} \mathrm{C}$. Besides that, the cellulose acetate membrane has a specific gravity ranging from 1.27-1.34 [2]. Cellulose acetate membranes have a high degree of bloat, low chemical resistance, weak electrical resistance, and small mechanical strength [2-4]. This causes the cellulose acetate membrane to have high flux but low selectivity. The selectivity of cellulose acetate membranes can be increased by zeolite addition [4-6]. An essential criterion for determining membrane effectiveness is to observe permeation and selectivity rates. The rate of permeation or flux is the rate of mass transfer per unit of membrane surface area per unit of time. This statement is formulated in Eq. 1 [7].

$\mathrm{J}=\frac{1}{\mathrm{~A}}\left(\frac{\mathrm{dm}}{\mathrm{dt}}\right)$ 
where $\mathrm{J}=$ total flux value $\left(\mathrm{g} / \mathrm{m}^{2} . \mathrm{h}\right), \mathrm{A}=$ membrane surface area $\left(\mathrm{m}^{2}\right), \mathrm{dm} / \mathrm{dt}=$ slope of the permeate mass curve over time.

Selectivity can be expressed by separation factor $(\alpha)$ Eq. 2 [7],

$\alpha=\frac{\left(\mathrm{Y}_{\mathrm{W}} / \mathrm{Y}_{\mathrm{A}}\right)}{\left(\mathrm{X}_{\mathrm{W}} / \mathrm{X}_{\mathrm{A}}\right)}$

where, $Y_{W}, Y_{A}=$ molar fractions of water $(W)$ and vetiverol (A) at the vapor phase in the permeate, $Y_{W}+Y_{A}$ $=1$; and $X_{W}, X_{A}=$ molar fractions of water $(\mathrm{W})$ and vetiverol (A) at the liquid phase in the feed, $X_{W}+X_{A}=1$.

Previous studies of modified cellulose acetate membranes with hydrophilic NaA zeolite fillers resulted in membranes that were densified that could increase membrane selectivity to hydrophilic materials [8-10]. Gamma irradiation of the cellulose acetate membrane by the addition of glutaraldehyde as a cross-linker can improve both physical and mechanical properties [11] evidenced by decreasing degrees of swelling and increased tensile strength. The addition of a stable N,N'-Methylene bis acrylamide as a cross-linker agent with crosslinking techniques can avoid degradation of irradiated membranes [12]. Modification of the membrane increases the membrane selectivity for pervaporation of hydrophilic materials. Pervaporation is a process of separating a volatile mixture by using a tight membrane regulated by a vacuum pump or carrier gas [7]. Pervaporation by using cellulose acetate membrane for extraction and separation of essential oils with the main component of hydrophilic compound (vetiverol) has been carried out, but the essential oil produced from vetiver has not had vetiverol level that meets SNI quality standard, so it needs to be improved [7]. The purpose of this research is to improve the physical and chemical characteristic of the membrane by increasing the polarity by adding $\mathrm{NaA}$ zeolite and the crosslinking between the bond of the cellulose acetate by adding N,N'Methylene bis acrylamide. Based on that, in this research, modified cellulose acetate membrane of rice husk with zeolite $\mathrm{NaA}$ and N,N'-Methylene bis acrylamide were irradiated by gamma-rays in the hope of producing a tight and selective membrane to vetiverol compound in vetiver oil by pervaporation methods. NaA zeolite has a high affinity [13]. Vetiver oil is one of the essential oils that contain a mixture of sesquiterpene alcohol and a very complex hydrocarbon. The main components of vetiver oil composition consist of sesquiterpene hydrocarbons $(\gamma$ cadinene, cloven, $\alpha$-amorphine, aromadendrene, juniper, and alcohol derivatives), vetiverol (khusimol, epiglobulol, spathulenol, khusinol, and carbonyl derivatives), and vetivone ( $\alpha$-vetivone, $\beta$-vetivone, khusimon and ester derivatives). Increased levels of vetiverol in vetiver oil can improve the quality of vetiver oil [14].

\section{- EXPERIMENTAL SECTION}

\section{Materials}

The rice husk used was from Cileles Village, Jatinangor District, vetiver oil was from Garut Regency. Glacial acetic acid, sulfuric acid, acetone, ethanol, hexane, chloride peroxide, methylene chloride, sodium hydroxide, sodium carbonate, potassium hydroxide, magnesium sulfate were obtained from Merck with p.a grade. Sodium chloride and Liquid nitrogen, N,N'Methylene bis acrylamide were from Merck and NaA zeolites were from Wiko (No. 267-00595).

\section{Procedure}

\section{Synthesis of CA-zeolite NaA-MBA membrane (CA-Z- MBA)}

Five percent w/v of CA polymer was dissolved in methylene chloride until homogeneous. Five percent w/v $\mathrm{NaA}$ zeolite of $5 \% \mathrm{w} / \mathrm{v}$ CA acetate weight was incorporated into the membrane solution while continuously stirring for $24 \mathrm{~h}$. It was then stored in the refrigerator for $24 \mathrm{~h}$ to avoid solvent evaporation and bubble removal. Then the membrane solution was printed on a glass plate. The membrane on the glass plate was stored in the desiccator until the membrane was detached from the glass plate. The formed membrane was soaked with MBA $1 \%$ for $10 \mathrm{~min}$ and stored in an air tight plastic [10].

\section{Irradiation of CA-Z-MBA membrane}

The CA-Z-MBA membranes in the airtight plastic was irradiated with various doses of 10, 20, 30 and $40 \mathrm{kGy}$. Irradiation was carried out by gamma rays from cobalt60 as the source [11].

\section{Pervaporation}

Pervaporation is a separation process by contacting 
the feed solution on the active side of one membrane surface. The result is a permeate in the form of vapor emitted on the other side of the membrane. The membrane was placed over the support horizontally on the apparatus of pervaporation. Into a flask, $100 \mathrm{~g}$ of vetiver oil was placed and heated to $40{ }^{\circ} \mathrm{C}$. The pervaporation process was carried out at a vacuum pressure $(0.5 \mathrm{mbar})$. Before and after the pervaporation process, the feed solution was taken slightly. Permeate was taken every one hour. Then the feed and permeate solution was calculated [4].

\section{Determination of ash content}

Samples were weighed as much as $1 \mathrm{~g}$ and fed into the already known weight plate, then inserted in the kiln and heated to a temperature of $600{ }^{\circ} \mathrm{C}$ for $4 \mathrm{~h}$. Then the samples were cooled in a desiccator and weighed. Ash content calculation was performed according to Eq. 3 [15].

$$
\text { Ash } \%=\frac{\text { Ash_Mass }}{\text { Sample_Mass }} \times 100
$$

\section{The degree of swelling}

The $3 \times 2 \mathrm{~cm}$ of CA membrane was weighed by dry weight, immersed in $10 \mathrm{~mL}$ of water at room temperature for $24 \mathrm{~h}$. The membrane surface was then dried with absorbent paper to remove excess water attached to the membrane surface. The wet membrane was weighed again several times until a constant weight $(\mathrm{Mb})$ was obtained, then the degree of swelling was calculated. Swelling degree (DS) of membrane can be determined by Eq. 4 [16].

$\mathrm{DS} \%=\frac{\mathrm{M}_{\mathrm{s}}-\mathrm{M}_{\mathrm{d}}}{\mathrm{M}_{\mathrm{d}}} \times 100$

where $M_{s}$ and $M_{d}$ are the mass of the swollen and dry membranes respectively.

\section{Membrane flux value}

The flux value determines the permeate obtained from the pervaporation process (Eq. 1) [7].

\section{Fourier-transform infra-red (FTIR)}

Membrane characterization using FTIR was conducted to determine functional groups present in the resulting membrane [2]. Cellulose acetate modified membrane with a weight of 1-2 mg was mashed mixed with $300-400 \mathrm{mg}$ of potassium bromide powder and put in a stainless steel cup. The infrared light absorption of the samples was measured in the region of wave numbers
$4000-500 \mathrm{~cm}^{-1}$. The IR spectra produced were compared with CA spectra before the copolymerization process.

\section{Scanning electron microscope (SEM)}

Membrane characterization using SEM was conducted to determine the morphological structure of the membrane and to perform cross-sectional analysis [2]. The samples were coated with Au then placed in a sample container on the SEM device, and afterwards the samples were closed and made airtight. The surface of the samples was then measured.

\section{Tensile strength (Ts)}

The modified CA membrane was cut to a plate with a width of $0.3 \mathrm{~cm}$ and its thickness was measured several times in the section of the cut membrane. After that, the membrane was tested for its tensile strength with the Stograph-RJ tool. The value of Ts was determined based on Eq. 5[3].

Ts $=\frac{\mathrm{m}}{\mathrm{t} \times \mathrm{l}}$

where $\mathrm{m}, \mathrm{t}$, and $\mathrm{l}$ are mass of tensile strength $(\mathrm{kg})$, thickness $(\mathrm{cm})$, and width $(\mathrm{cm})$ of the membranes, respectively.

\section{Crosslinking yield}

The crosslinking yield (CY) was determined by Eq. 6 [17].

$\mathrm{CY} \%=\frac{\mathrm{M}_{\mathrm{x}}-\mathrm{M}_{\mathrm{y}}}{\mathrm{M}_{\mathrm{y}}} \times 100$

where $M_{y}$ and $M_{x}$ are the mass of the membrane before and after crosslinking, respectively.

\section{Vetiverol in vetiver oil}

Concentration of vetiverol in the permeate (CP) and vetiverol in the feed $(\mathrm{CF})$ were calculated from ester numbers before acetylation and ester numbers after acetylation according to SNI 06-2386-2006. The ester number of CA before acetylation was determined by the addition of $25 \mathrm{~mL}$ of $0.5 \mathrm{~N} \mathrm{KOH}$ to each sample and blank, which was then refluxed for $1 \mathrm{~h}$. Phenolphthalein was added to the mixture solution then titrated with $0.5 \mathrm{~N}$ $\mathrm{HCl}$ to a color change. The ester number before acetylation was calculated according to Eq. 7.

The ester number after acetylation was determined by adding $10 \mathrm{~mL}$ acetic anhydride and $2 \mathrm{~g}$ sodium silicate 
anhydride to $10 \mathrm{~mL}$ of sample. The solution mixture was refluxed for $2 \mathrm{~h}$, cooled, and added with $50 \mathrm{~mL}$ of water. The mixture solution was heated at $40^{\circ} \mathrm{C}$ for $15 \mathrm{~min}$, stirred and inserted into a separating funnel and washed with $10 \mathrm{~mL}$ of water. The oil layer was separated by a layer of water. $50 \mathrm{~mL}$ of sodium chloride, $50 \mathrm{~mL}$ of $\mathrm{Na}_{2} \mathrm{CO}_{3} / \mathrm{NaCl}$, $20 \mathrm{~mL}$ of water and $3 \mathrm{~g} \mathrm{MgSO}_{4}$ were then added to the oil layer. The essential oil was weighed and added with $2 \mathrm{~mL}$ of water and phenolphthalein. Then $25 \mathrm{~mL}$ of ethanol/ $\mathrm{KOH} 0.5 \mathrm{M}$ was added to the solution mixture, refluxed for $1 \mathrm{~h}$, then cooled by adding $20 \mathrm{~mL}$ of water. The solution mixture was titrated with $0.5 \mathrm{M} \mathrm{HCl}$ and the ester number after acetylation was calculated according to the equation $\mathrm{E}_{2}$. Vetiverol concentration was determined by Eq. 9 [11]. $\mathrm{E}_{1}($ The ester number before acetylation $)=\frac{56.1\left(\mathrm{~V}_{1}-\mathrm{V}_{0}\right) \mathrm{N}}{\mathrm{m}}$

$\mathrm{E}_{2}($ The ester number after acetylation $)=\frac{28.05(\mathrm{a}-\mathrm{b})}{\mathrm{c}}$

Vetiverol concentration $=\frac{M\left(E_{2}-E_{1}\right)}{561-0.42 \times E_{2}}$

where: $\mathrm{m}=$ mass of sample before acetylation $/ \mathrm{g}, \mathrm{V}_{1}=$ volume of $0.5 \mathrm{~N} \mathrm{HCl}$ for the blank titration $/ \mathrm{mL}, \mathrm{V}_{0}=0.5$ $\mathrm{N} \mathrm{HCl}$ volume for sample titration/mL, $\mathrm{N}=$ acidity of $\mathrm{HCl}, \mathrm{a}=$ volume of $0.5 \mathrm{~N} \mathrm{HCl}$ for the blank titration $/ \mathrm{mL}$, $\mathrm{b}=$ volume of $0.5 \mathrm{~N} \mathrm{HCl}$ for sample titration $/ \mathrm{mL}, \mathrm{c}=$ sample mass after acetylation/g, $\mathrm{M}=$ molecular mass of vetiverol/g, $\mathrm{E}_{1}=$ ester number after acetylation, $\mathrm{E}_{2}=$ ester number before acetylation.

\section{- RESULTS AND DISCUSSION}

\section{Cellulose Isolation from Rice Husk}

Cellulose isolation was carried out through 3 stages: 1) Dissolving with potassium carbonate, 2) alkali treatment (1.5\% hydrogen peroxide and $5 \mathrm{~N}$ sodium hydroxide $\mathrm{pH}$ 11 ), and 3 ) delignification ( $70 \%$ nitric acid and $80 \%$ acetic acid). At the dissolving process using potassium carbonate, the cellulose content increased from 46.50 to $77.03 \%$, but the silica content decreased from 20.20 to $2.02 \%$. The dissolution process with potassium carbonate in water resulted in the bonding of hydroxide ion (Eq. 10) to silica (Eq. 11).

$$
\begin{aligned}
& \mathrm{CO}_{3}{ }^{2-}{ }_{(\mathrm{aq})}+\mathrm{H}_{2} \mathrm{O}_{(\mathrm{l})} \rightarrow \mathrm{HCO}_{3}{ }_{(\mathrm{aq})}+\mathrm{OH}^{-}{ }_{(\mathrm{aq})} \\
& 2 \mathrm{OH}^{-}{ }_{(\mathrm{aq})}+\mathrm{SiO}_{2(\mathrm{~s})} \rightarrow \mathrm{SiO}_{3}{ }^{2-}{ }_{(\mathrm{aq})}+\mathrm{H}_{2} \mathrm{O}_{(\mathrm{l})}
\end{aligned}
$$

The decrease in lignin levels and hemicellulose levels (Table 1) was due to the potassium carbonate solution [18]. However, at this stage the lignin production was still high (16.98\%), which can disturb the cellulose isolation process, so it was necessary to perform alkali treatment [19]. At the alkali treatment stage, the cellulose content increased up to $77.08 \%$ but there was a decrease in lignin reaching $6.02 \%$ as well as a decrease in hemicellulose and silica levels (Table 1).

Alkali treatment was done to separate cellulose, lignin, and hemicellulose because of the presence of hydroxide ions (Eq. 12, 13). At this stage, the lignocellulose bonds degraded and caused a decrease in lignin and hemicellulose levels, but increased the cellulose levels. The addition of sodium hydroxide at $\mathrm{pH} 11$ caused the degree of polymerization and crystallization properties of lignocellulose bond to decrease. The reaction in alkaline conditions can extract the silica [20-21].

$$
\begin{aligned}
& \mathrm{H}_{2} \mathrm{O}_{2} \leftrightarrow \mathrm{HOO}^{-}+\mathrm{H}^{+} \\
& \mathrm{H}_{2} \mathrm{O}_{2}+\mathrm{HOO}^{-} \leftrightarrow \mathrm{H}_{2} \mathrm{O}+\mathrm{HO}^{-}+\mathrm{O}_{2}
\end{aligned}
$$

Delignification with $70 \%$ nitric acid and $80 \%$ acetic acid (catalyst) protected the cellulose, but broke the lignin bond, and reduced the silica and hemicellulose levels reaching close to $0 \%$. The resulting lignin content (2.02\%) did not affect the process of cellulose isolation [22].

\section{Type of Cellulose Acetate (CA)}

The preparation of CA from rice husk was conducted through the activation, the acetylation process, and the hydrolysis process. The activation stage

Table 1. Content of silica, cellulose, hemi-cellulose and lignin in rice husk at each stage

\begin{tabular}{lrccc}
\hline \multirow{2}{*}{ Stages } & \multicolumn{4}{c}{ Content (\%) } \\
\cline { 2 - 5 } & Silica & Cellulose & Hemicellulose & Lignin \\
\hline Rice Husk & 20.20 & 46.50 & 10.24 & 22.52 \\
Dissolution with Potassium Carbonate 1:3.5 & 2.02 & 77.03 & 0.17 & 16.98 \\
Alkali treatment & 1.62 & 77.08 & 0.08 & 6.21 \\
Delignification & 0.62 & 93.32 & 0.07 & 2.20 \\
\hline
\end{tabular}


was carried out by the addition of glacial acetic acid which inflated the cellulose structure and enlarged the surface area on the cellulose which lead to increased reactivity to the acetyl group, causing the acetylation process to take place quickly [2]. The acetylation process was carried out by addition of acetic acid anhydride and sulphuric acid as a catalyst. Acetic acid anhydride serves to substitute acetyl groups in hydroxyl groups of the cellulose. The acetylation process is an exothermic reaction, so it was carried out at room temperature to keep the cellulose structure from being degraded. The homogeneous mixture of the solution successfully characterized the acetylation reaction. The hydrolysis process discontinued the acetylation reaction by the addition of $80 \%$ acetic acid [2]. The hydrolysis process was carried out in order to release the acetyl group and to remove the residual unreacted acetic acid anhydride. The acetyl content of CA was $43.87 \%$, which indicated that the type of cellulose was cellulose triacetate [2]. The cellulose triacetate was used as the base material of the CA membrane.

\section{The Crosslinking Yield and Degree of Swelling}

Fig. 1 and 2 show the crosslinking yield and degree of swelling of the irradiated CA-Z-MBA membrane. The density of the membrane was determined from the crosslinking yield of CA-Z-MBA membrane [3]. Fig. 1 shows that the crosslinking yield of CA-Z-MBA increased up to $14.28 \%$ at doses of $0-30 \mathrm{kGy}$ indicating the number of bonds formed -between the cross-linkers and the CA

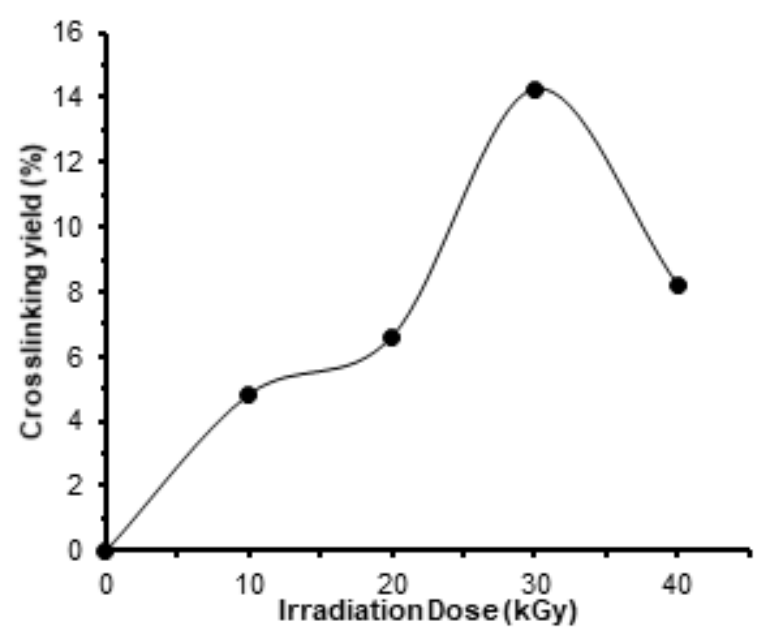

Fig 1. Crosslinking yield of CA-Z-MBA membrane at different irradiation dose causing the membrane to become closer [23]. Fig. 2 shows that the CA- $Z$ membrane had the degree of swelling of $8.57 \%$, then decreased to $4 \%$ by adding $1 \%$ MBA at an irradiation dose of $30 \mathrm{kGy}$.

The crosslinking occurred after irradiation in the presence of MBA. As a result, water absorption capacity of the membrane was less due to the smaller pores formed [12,24]. The degree of swelling of CA-Z-MBA increased at an irradiation dose of $40 \mathrm{kGy}$ from 4 to 7.14\% (Fig. 2) due to the CA degradation. At irradiation dose of $40 \mathrm{kGy}$, the CA started degradation which opened the membrane pores, causing the water to diffuse more. The phenomena can be seen from the result of cross-linking which decreased (14.28 to 8.22\%) at Fig. 1. High radiation energy resulted in the breaking of the bond of the CA polymer [12].

\section{Mechanical Properties}

The mechanical properties of modified CA-ZMBA membrane can be seen by the results of the tensile strength test (Ts) shown in Fig. 3.

The Ts of CA-MBA and CA-Z-MBA increased at a dose of 10 to $30 \mathrm{kGy}$. Up to irradiation dose of $30 \mathrm{kGy}$ the CA-MBA-membrane gave high Ts. The increase in Ts was due to the formation of polymer bonds between CA with the cross-linkers MBA as the binding bridge, which caused the membrane to become tighter. However, the Ts of CA-Z-MBA-membrane at a dose of 10 to $30 \mathrm{kGy}$ was higher than that of the CA-MBA membrane. The high

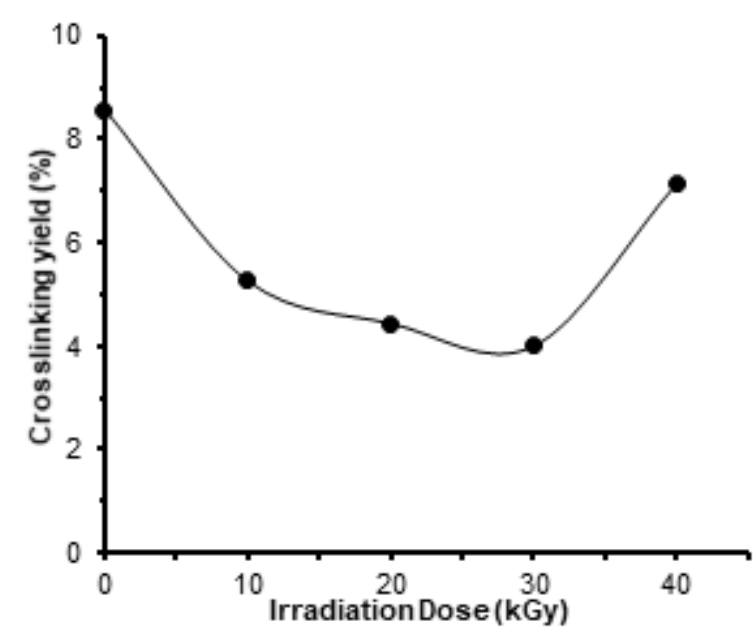

Fig 2. Degree of swelling of CA-Z-MBA membrane at different irradiation dose 


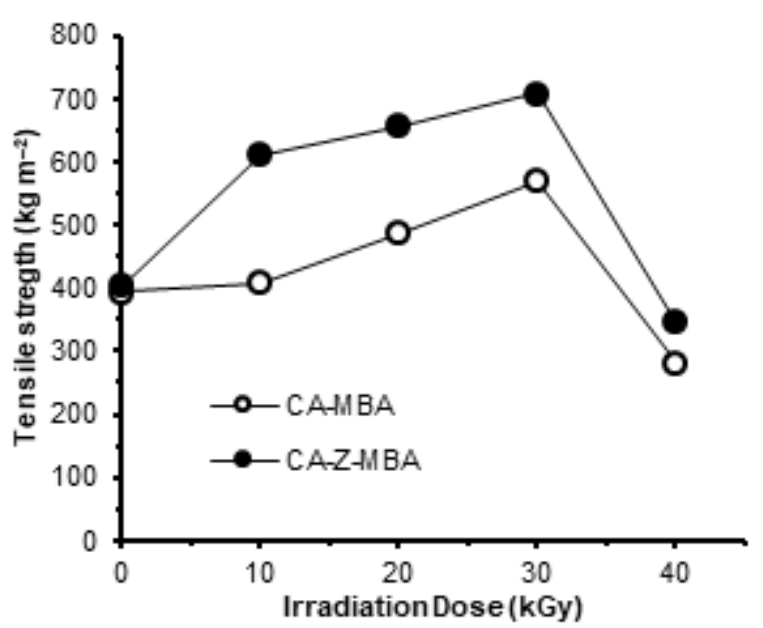

Fig 3. The tensile strength of CA-MBA and CA-Z-MBA membranes

Ts of the CA-Z-MBA membrane indicated the effect of the NaA zeolite filler on the void of the membrane that improved the mechanical properties. The presence of MBA increased the tensile strength of the membrane due to the bonds formed between the polymer matrix and the cross-linker [23]. Based on the data, it can be said that the irradiated CA-Z-MBA membrane at irradiation dose up to $30 \mathrm{kGy}$ improved the mechanical properties. At irradiation dose of $40 \mathrm{kGy}$, the Ts decreased due to the degradation on the backbone of CA caused by high irradiation dose.

\section{The Functional Group Analysis}

The FTIR spectra of CA and irradiated CA-Z-MBA membrane at irradiation dose of $20 \mathrm{kGy}$ is shown in Fig. 4. There is no significant difference between the spectra of the CA membrane and the CA-Z-MBA membrane. The results of FTIR spectra show that there is shifting of the wavenumber in the typical region of absorption of the $\mathrm{O}-\mathrm{H}$ group from 3488 to $3487 \mathrm{~cm}^{-1}$. The wavenumber shifted due to the location of the $\mathrm{O}-\mathrm{H}$ group on the $\mathrm{CA}$ that resulted from the reaction of free radical formation in the group $\mathrm{O}$, which binds to the $\mathrm{C}=\mathrm{O}$ group of $\mathrm{MBA}$. The wavenumber shift also occurred in the $\mathrm{C}=\mathrm{O}$ uptake region derived from the acetyl group on the $\mathrm{SA}$ matrix from 1638 to $1670 \mathrm{~cm}^{-1}$. The shift of $\mathrm{C}=\mathrm{O}$ happened because of environmental changes (adjacent neighboring groups) of the acetyl groups. Also amplified by the number of waves at $1527 \mathrm{~cm}^{-1}$ which is characteristic of the $\mathrm{N}-\mathrm{H}$ group on the MBA. The absorption of the $\mathrm{N}-$ $\mathrm{H}\left(1527 \mathrm{~cm}^{-1}\right)$ group in addition to $\mathrm{C}=\mathrm{O}\left(1670 \mathrm{~cm}^{-1}\right)$ group uptake is characteristic of the amide compound from the MBA [23]. From the FTIR spectra analysis of the CA membrane and irradiated CA-Z-MBA membrane the formation of a bond between MBA with the CA matrix can be observed.

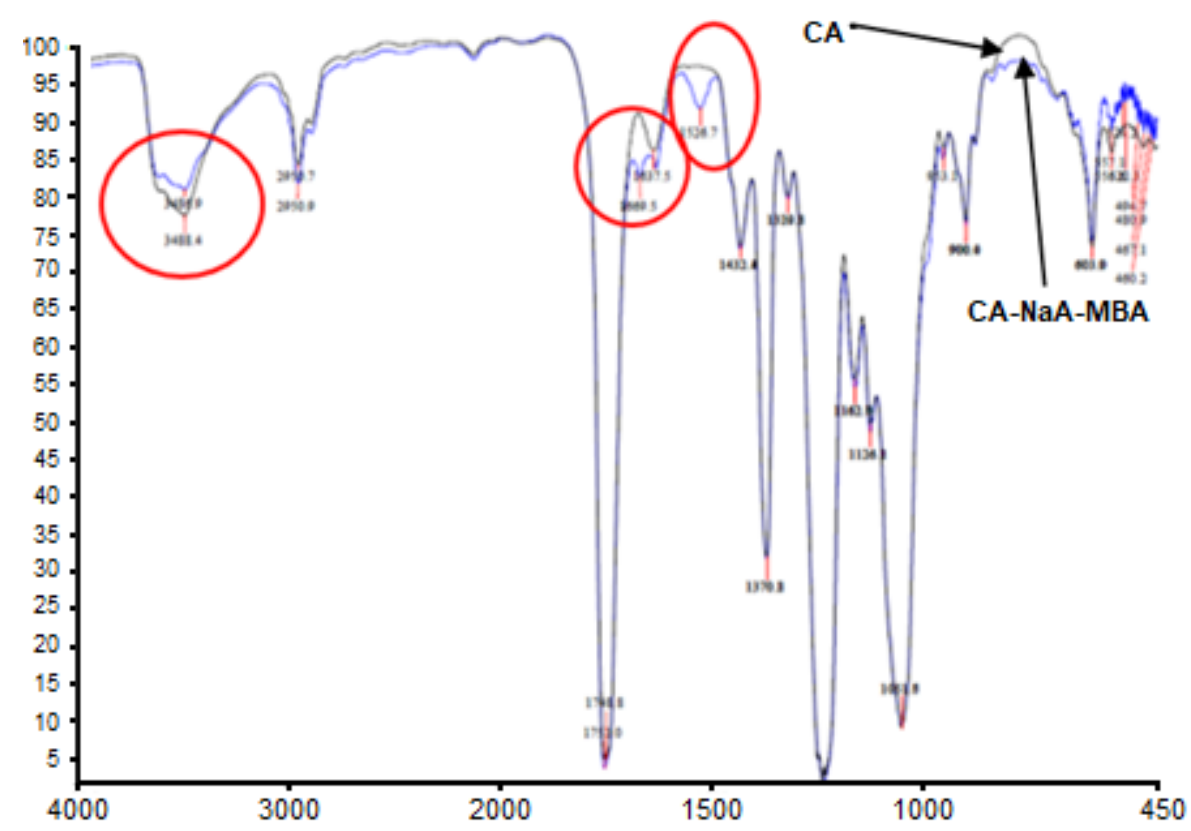

Fig 4. The FTIR spectra of CA membrane and irradiated CA-Z-MBA membrane (Irradiation dose of $20 \mathrm{kGy}$ ) 
Fig. 5 shows the description of the reaction between the $\mathrm{CA}$ as a polymer matrix and MBA as a cross-linking agent irradiated by gamma-rays. The MBA functions as a cross-linker between two cellulose acetate bonds, which replaced the $\mathrm{H}^{+}$on the cellulose acetate.

\section{The Morphology Analysis}

The SEM analysis of the cross-section of the CA membrane and the CA-Z-MBA membrane is shown in Fig. 6. The CA-Z-MBA membrane (Fig. 6(b)) has a dense and orderly structure morphology compared to the CA membrane (Fig. 6(a)). The dense and orderly structure is due to the presence of $\mathrm{NaA}$ zeolites and the addition of MBA as a cross-linker agent to the CA membrane, causing closer and stronger bonding of the CA polymer [10,24]. The statement mentioned above is supported by the data

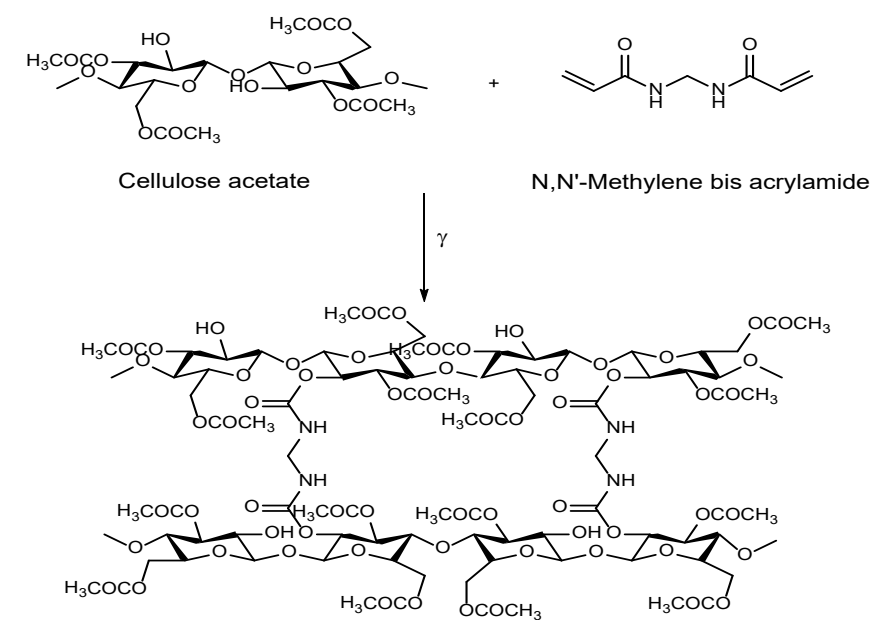

Fig 5. The reaction of cellulose acetate as polymer matrix with N,N'-Methylene bis acrylamide as cross-linker

(a)

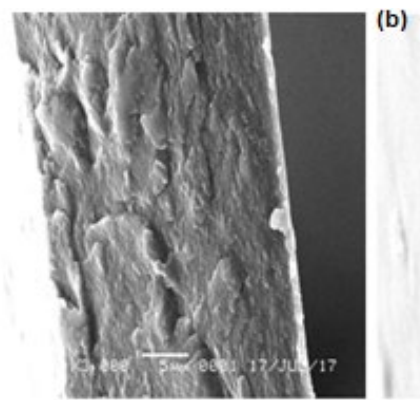

Fig 6. (a) Cross section of the CA membrane, and (b) the irradiated CA-Z-MBA membrane (irradiation dose of $20 \mathrm{kGy}$ ) of crosslinking yield and degree of swelling of irradiated CA-Z-MBA membrane at an irradiation dose of $20 \mathrm{kGy}$ (Fig. 1 and 2). The irradiated CA-Z-MBA membrane has a higher crosslinking yield and a lower degree of swelling compared to the CA membrane. Furthermore, it is supported by the higher tensile strength data of the irradiated CA-Z-MBA membrane compared to the CA membrane (Fig. 3). However, the CA-Z-MBA membrane is denser than the CA membrane.

\section{Pervaporation of Vetiverol in Vetiver Oil}

Pervaporation is a separation process done by contacting the feed solution on the active side on one of the membrane surfaces, while the result is a permeate released in the form of a vapor on the other side of the membrane [24]. The pervaporation process is conducted at a temperature of $40^{\circ} \mathrm{C}$ because this temperature is the optimal temperature of the pervaporation process. The membrane is placed on the supporting module, resulting in a flow of cross flow, so the non-via membrane feed returns into the flask [24]. The interaction between a hydrophilic vetiverol compound and a hydrophilic CAZ-MBA-membrane show that separation takes place through the diffusion of the membrane with hydrophilic properties. The resulting permeate turns into a gas phase due to the different pressures, atmospheric pressure at the feed side and 0.5 mbar vacuum pressure on the permeate side so that liquid nitrogen is required to convert the gas phase into a solid phase so as not to be missed to the pump on the device leading to the silica pile. The permeate is accommodated 4 times every hour and measured [3]. The CA-Z-MBA-membrane that had been characterized was analyzed using a pervaporation device to determine its performance (flux value) and the resulting permeate concentration (CP). The flux and $\mathrm{CP}$ of the membrane in the pervaporation process can be seen in Fig. 7 .

It can be seen that the $\mathrm{CP}$ value of the irradiated CA-Z-MBA membrane increased by increasing the irradiation dose. The highest $C P$ value obtained on the CA-Z-MBA membrane was at irradiation dose of $30 \mathrm{kGy}$ (13.47\%) evidenced by the highest crosslinking yield (14.28\%) with the smallest degree of swelling (4\%), but the 


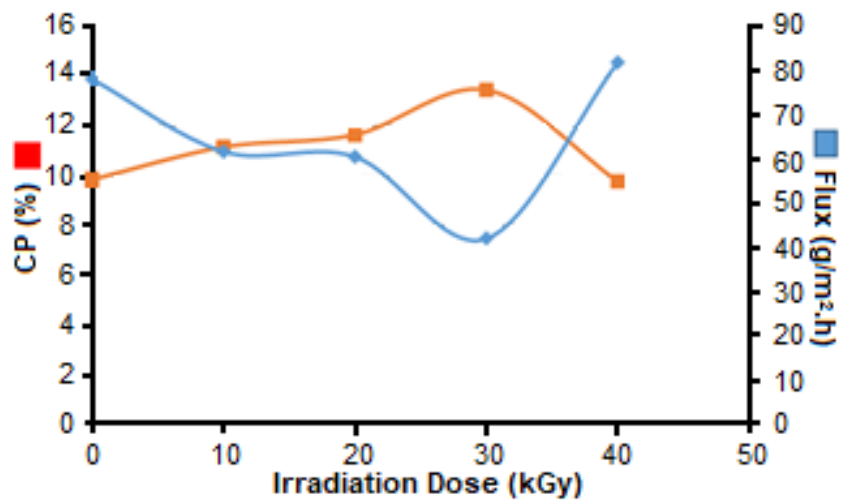

Fig 7. The effect of irradiation dose-on flux and $\mathrm{Cp}$ of irradiated CA-Z-MBA membrane

resulting flux dropped dramatically as the membrane becomes denser compared to the CA-Z-MBA membrane irradiated at dose of $20 \mathrm{kGy}$, evidenced by the increased tensile strength of the CA-Z-MBA membrane at irradiation dose of $30 \mathrm{kGy}$ (Fig. 3). The decrease of flux causes the pervaporation to take place slowly. The pervaporation process is optimal if permeate concentration (CP) rises gradually but the flux does not decrease drastically. The CA-Z-MBA membrane irradiated at a dose of $20 \mathrm{kGy}$ reached the flux of $60.58 \mathrm{~g} / \mathrm{m}^{2}$.h and CP of $11.67 \%$. The $\mathrm{CP}$ increased 5 times from 2.40 to $11.67 \%$.

\section{- CONCLUSION}

Radiation induced crosslinking of CA-Z-MBA membranes using gamma rays, decreased the degree of swelling, and increased the tensile strength of the membrane. The optimum dose of irradiation of the modified membrane was $20 \mathrm{kGy}$ with crosslinking yield of $6.61 \%$, degree of swelling of $4.44 \%$, and a tensile strength of $656.40 \mathrm{~kg} / \mathrm{m}^{2}$. The addition of zeolite NaA stimulated vetiverol in vetiver oil using pervaporation methods. Performance of the CA-Z-MBA membrane resulted in flux of $60.58 \mathrm{~g} / \mathrm{m}^{2} . \mathrm{h}$ and CP of $11.67 \%$ where the vetiverol level increased 5 times from 2.40 to $11.67 \%$.

\section{- ACKNOWLEDGMENTS}

The authors would like to thank CIRA-National Nuclear Energy Agency (NNEA) and Faculty of Mathematics and Natural Sciences, Padjadjaran University for funding this study. We also thank Mr. Santoso Prayitno, and Mr. Supandi from CIRA-NNEA for experimental help in this work and Dr. Mardiyanto from AMC-NNEA for the suggestions.

\section{- REFERENCES}

[1] Kusworo, T.D., Soetrisnanto, D., Widayat, Budiyono, and Utomo, D.P., 2018, Study of polymeric, membranes potential for eugenol purification from crude clove leaf oil, ASEAN $J$. Chem. Eng., 18 (2), 81-92.

[2] Etemadi, H., Yegani, R., Seyfollahi, M., and Rabiee, M., 2018, Synthesis, characterization, and antifouling properties of cellulose acetate/polyethylene glycol-grafted nanodiamond nano composite membranes for humic acid removal from contaminated water, Iran. Polym. J., 27 (6), 381-393.

[3] Das, A.M., Ali, A.A., and Hazarika, M.P., 2014, Synthesis and characterization of cellulose acetate from rice husk: Eco-friendly condition, Carbohydr. Polym., 112, 342-349.

[4] Zheng, P.Y., Zhang, W.H., Li, C., Wang, N.X., Li, J., Qin, Z.P., and An, Q.F., 2019, Efficient bio-ethanol recovery by non-contact vapor permeation process using membranes with tailored pore size and hydrophobicity, Chem. Eng. Sci., 207, 448-455.

[5] Ernawati, E., 2014, Pembuatan membran selulosa asetat termodifikasi zeolit alam Lampung untuk pemisahan etanol-air secara pervaporasi, Chimica at Natura Acta, 2 (1), 101-104.

[6] Fu, Y.J., Lai, C.L., Chen, J.T., Liu, C.T., Huang, S.H., Hung, W.S., Hu, C.C., and Lee, K.R., 2014, Hydrophobic composite membranes for separating of water-alcohol mixture by pervaporation at high temperature, Chem. Eng. Sci., 111, 203-210.

[7] Jyoti, G., Keshav, A., and Anandkumar, J., 2015, Review on pervaporation: Theory, membrane performance, and application to intensification of esterification reaction, J. Eng., 2015, 927068.

[8] Sarialp, G., 2012, Dehydration of aqueous aprotic solvent mixtures by pervaporation, Thesis, Department of Engineering, Middle East Technical University, Turkey.

[9] Iryani, D.A., Wulandari, N.F., Cindradewi, A.W., Ginting, S., Ernawati, E., and Hasanudin, E., 2018, 
Lampung natural zeolite filled cellulose acetate membrane for pervaporation of ethanol-water mixtures, IOP Conf. Ser.: Earth Environ. Sci., 141, 012013.

[10] Wee, S.L., Tye, C.T., and Bhatia, S., 2008, Membrane separation process - Pervaporation through zeolite membrane, Sep. Purif. Technol., 63 (3), 500-516.

[11] Suhartini, M., and Ernawati, E.E., 2014, Karakteristik kopolimer radiasi selulosa asetat-ko-glutaraldehida, Jusami, 15 (4), 214-220.

[12] Becker, W., and Schmidt-Naake, G., 2002, Proton exchange membranes by irradiation induced grafting of styrene onto FEP and ETFE: Influences of the crosslinker N,N-methylene-bis-acrylamide, Chem. Eng. Technol., 25 (4), 373-377.

[13] Kristóf, T., 2017, Selective removal of hydrogen sulphide from industrial gas mixture using zeolite NaA, Hung. J. Ind. Chem., 45 (1), 9-15.

[14] Mulyono, E., Sumangat, D., and Hidayat, T., 2012, Peningkatan mutu dan efisiensi produksi minyak akar wangi melalui teknologi penyulingan dengan tekanan uap bertahap, Buletin Teknologi Pascapanen Pertanian, 8 (1), 35-47.

[15] Sluiter, A., Hames, B.V., Ruiz, R., Scarlata, C., Sluiter, J., and Templeton, D., 2008, Determination of ash in biomass - Laboratory analytical procedure (LAP), Technical Report NREL/TP-510-42622, National Renewable Energy Laboratory, U.S. Department of Energy, Colorado, USA.

[16] Gierszewska-Drużyńska, M., and OstrowskaCzubenko, J., 2015, Structural and swelling properties of hydrogel membranes based on chitosan crosslinked with glutaraldehyde and sodium tripolyphosphate, Prog. Chem. Appl. Chitin Deriv., 20, 43-53.

[17] Suleman, M.S., Lau, K.K., and Yeong, Y.F., 2016, Characterization and performance evaluation of PDMS/PSF membrane for $\mathrm{CO}_{2} / \mathrm{CH}_{4}$ separation under the effect of swelling, Procedia Eng., 148, 176-183.

[18] Rosa, S.M.L., Rehman, N., de Miranda, M.I.G., Nachtigall, S.M.B., and Bica, C.I.D., 2012, Chlorinefree extraction of cellulose from rice husk and whisker isolation, Carbohydr. Polym., 87 (2), 11311138 .

[19] Bazargan, A., Gebreegziabher, T., Hui, C.W., and McKay, G., 2014, The Effect of alkali treatment on rice husk moisture content and drying kinetics, Biomass Bioenergy, 70, 468-473.

[20] Watkins, D., Nuruddin, M., Hosur, M., TcherbiNarteh, A., and Jeelani, S., 2015, Extraction and characterization of lignin from different biomass resources, J. Mater. Res. Technol., 4 (1), 26-32.

[21] Ab Ghani, M.H., Royan, N.R.R., Kang, S.W., Sulong, A.B., and Ahmad, S., 2015, Effect of alkaline treated rice husk on the mechanical and morphological properties of recycled HDPE/RH Composite, J. Appl. Sci. Agric., 10 (5), 138-144.

[22] Wang, Z., Li, J., Barforf, J.P., Hellgrandt, K., and McKay, G., 2016, A comparison of chemical treatment methods for the preparation of rice husk cellulosic fibers, Int. J. Environ. Agric. Res., 2 (1), 67-77.

[23] Muñoz-García, R.O., Hernandez, M.E., Ortiz, G.G., Fernández, V.V.A., Arellano, M.R., and SánchezDíaz, J.C., 2015, A novel polyacrylamide-based hydrogel crosslinked with cellulose acetate and prepared by precipitation polymerization, Quim. Nova, 38 (8), 1031-1036.

[24] Hunger, K., Schmeling, N., Jeazet, H.B.T., Janiak, C., Staudt, C., and Kleinermanns, K., 2012, Investigation of cross-linked and additive containing polymer materials for membranes with improved performance in pervaporation and gas separation, Membranes, 2 (4), 727-763. 